\title{
REFLEXÕES ACERCA DA SÉRIE THE BOYS: APROXIMAÇÕES ENTRE O BEM E MAL, INTERSEÇÕES ENTRE A FICÇÃO E A REALIDADE
}

Laura Cristina de Toledo Quadros Leticia de Toledo Quadros Musco

Recebido em 21 fev 2021. Laura Cristina de Toledo Quadros

Aprovado em 10 abr 2021. Doutora em Psicologia pelo Programa de Pós-graduação em Psicologia Social (UERJ).

Professora Adjunta da Universidade do Estado do Rio de Janeiro (UERJ).

Colaboradora e coordenadora adjunta do Programa de Pós-graduação em Psicologia Social (UERJ).

Coordenadora do projeto de extensão (UERJ) COMtextos: arte e livre expressão na abordagem gestáltica.

http://lattes.cnpq.br/5917221201880680

auractq@gmail.com

https://orcid.org/0000-0002-3546-4935

Leticia de Toledo Quadros Musco

Graduanda em Psicologia (UERJ) e em Comunicação Social com ênfase em jornalismo (PUC).

Bolsista de Iniciação Científica (PIBIC-UERJ) no Laboratório de Estudos em Mídia e Esporte.

http://lattes.cnpq.br/9186564539017837

lettquadros@gmail.com

https://orcid.org/0000-0002-9291-4592

Resumo: Este artigo tem por objetivo fazer uma interseção entre elementos presentes na série 
americana The Boys com temas e situações pertinentes à sociedade e ao sujeito moderno, considerando como as narrativas propostas na série, mesmo representando um mundo fantasioso, atravessam de modo nada sutil o chamado "mundo real". Dentre as inúmeras possibilidades de reflexões que The Boys nos proporciona, escolhemos abordar as desvirtudes dos heróis não reduzidas a dicotomia entre o bem e o mal, passando pelo deslocamento dos estereótipos para os arquétipos. Recorremos a temas que envolvem questões estruturais, culturais e filosóficas que fazem com que a série seja tão pertinente, cativante e, principalmente, familiar ao espectador. Por fim, ressalta-se a importância de uma narrativa que coloque conflitos em cena de modo não maniqueísta, promovendo reflexões acerca da aproximação entre a ficção e a realidade.

Palavras-chave: The Boys. Super-heróis. Narrativas. Ficção e realidade.

Abstract: This article aims to make an intersection between elements present in the American series The Boys with themes and situations pertinent to society and the modern subject, considering how the narratives proposed in the series, even representing a fantastic world, cross in a not subtle way the socalled "real world". Among the numerous possibilities of reflections that The Boys provides us with, we have chosen to approach the deviations of heroes not reduced to the dichotomy between good and evil, going through the displacement of stereotypes to archetypes. We resort to themes involving structural, cultural, and philosophical issues that make the series so pertinent, captivating, and, above all, familiar to the viewer. Finally, we emphasize the importance of a narrative that puts conflicts on the stage in a nonmanichean way, promoting reflections about the approximation between fiction and reality.

Keywords: The Boys. Superheroes. Narratives. Fiction and reality. 


\section{INTRODUÇÃO}

O presente artigo tem por objetivo fazer uma interseção entre elementos presentes na série norte-americana The Boys com temas e situações pertinentes à sociedade e ao sujeito moderno, considerando como as narrativas propostas na série, mesmo representando um mundo fantasioso, atravessam de modo nada sutil o chamado "mundo real". Nesse sentido, ficção e realidade dialogam tanto em metáforas, quanto em confluências nas quais a prevalência das dicotomias herói-vilão, bem-mal se fazem marcadas, mas também têm suas fronteiras borradas, tal e qual observamos na sociedade atual, numa certa distopia contemporânea. Vale destacar que a série ainda está em andamento, com previsão de lançamento da terceira temporada em 2021, figurando em várias listas de comentaristas como umas das melhores séries de 2020.

Imagine acordar de manhã, ligar a televisão e ver a notícia de que o Capitão Pátria tinha acabado de salvar reféns de um ônibus na rua mais movimentada da cidade. Distante para nós, mas uma manhã normal para a população da série de ficção científica The Boys. Pessoas agraciadas por Deus com superpoderes que outros habitantes não têm. Entre os heróis, um grupo se destaca, os Seven. Um seleto grupo, do qual todos os Supers (modo como os heróis são chamados) querem fazer parte e que, é claro, tem o acompanhamento de uma espécie de multinacional. Quantas vezes somos levados a imaginar que um mundo com super-heróis poderia ser menos violento, mais justo, sem guerras, fome ou desigualdade? The Boys, entretanto, nos mostra a outra face dessa moeda, 
explorando o cinismo, a corrupção e a violência em uma sociedade protegida, justamente, por seus heróis. A série não é apenas uma série de super-heróis. É uma série que fala sobre o poder das grandes corporações, sobre manipulação e sobre tudo aquilo que não queremos falar na nossa sociedade. Mesmo sendo enredada por uma narrativa de ficção científica, ela dispõe de aspectos que aproximam a trama do público que a assiste, e pode ser resumida em uma frase do século XIX: "o poder corrompe, o poder absoluto corrompe absolutamente" (Lord Acton) ${ }^{1}$.

Ao mencionar The Boys, é importante atentarmo-nos para um aspecto interessante. A ideia original de um mundo no qual super-heróis têm seus declínios morais foi lançada em 2006, pelo roteirista de histórias em quadrinho Garth Ennis. Inicialmente publicada pela DC Comics, após seis edições, a editora decidiu cancelar a continuidade do produto pelo incômodo que ela gerava. As demais edições, então, passaram a ser publicadas pela Dynamite Entertainment. Apesar do relativo sucesso à época, com duas indicações em 2008 e 2010 nas categorias "melhor série" (Eisner Awards) e "melhor livro de quadrinhos" (Scream Awards) respectivamente, foi através da sua adaptação para a plataforma de streaming Prime Video, em 2019, que The Boys despontou como um grande sucesso de público. A série teve mais de 50 milhões de visualizações por dia até a quinta semana após seu lançamento, mais do que o dobro de qualquer série da Marvel na Netflix².

1 Disponível em: https://pt.wikipedia.org/wiki/John_DalbergActon,_1.\%C2\%BA_ Bar\%C3\%A3o_Acton. Acesso em: 20 fev. 2021.

2 YAO, Rodrigo. The Boys já fez mais sucesso que qualquer série da Marvel na Netflix; confira os números! Observatório de Séries. [S. I.], 15 set. 2019. Disponível em: https:// observatoriodeseries.uol.com.br/destaque/the-boys-ja-fez-mais-sucesso-quequalquer-serie-da-marvel-na-netflix-confira-os-numeros. Acesso em: 20 fev.2021. 
Para além de mostrar super-heróis usando drogas ou tendo atitudes moralmente contestáveis diante de suas posições, a série apresenta uma grande crítica social a partir de elementos atuais que atravessam a existência do sujeito moderno, sendo geradores de tensões e conflitos de ordem moral e social.

\section{APRESENTANDO A SÉRIE}

A série começa com Robin, a namorada de Hughie Campbell (Jack Quaid) sendo desintegrada na frente do namorado por Trem-Bala (Jessie Usher), um super-herói, membro dos Seven. A partir desse episódio, Hughie tenta buscar por justiça pelo assassinato de Robin, enquanto a Vought International, poderosa corporação que detém os direitos pelos Supers (os heróis), tenta buscar um acordo amigável, distorcendo os fatos, para minimizar a culpa de Trem-Bala e oferecendo uma grande quantia em dinheiro a Hughie para que ele nunca mais toque no assunto. Incomodado e inconformado com a situação, o jovem rapaz é contatado por Billy Butcher (Karl Urban), um ex-agente da CIA, que nutre grande ódio pelos Supers e deseja destruílos e, particularmente, se vingar de Capitão Pátria, por acreditar que este tem ligação com o desaparecimento de sua esposa, ocorrido há alguns anos.

Conforme as situações vão acontecendo, Butcher chama mais dois parceiros para, junto com ele e Hughie, unirem-se no combate aos heróis: Frenchie e Mothers' Milk. Os dois não se dão muito bem, devido a um desentendimento em outra ação na qual trabalharam juntos. Entretanto, a pedido de Butcher, eles aceitam o trabalho, não sem relutarem. Assim, forma-se o grupo dos 
Boys, rapazes 'comuns' que se unem e agem diante de um único objetivo: acabar com os Supers e com a Vought.

Em paralelo a isso, o espectador é apresentado a Annie January (Erin Moriaty), também conhecida como Luz-Estrela, cujo sonho (seu e de sua mãe) é entrar para o seleto grupo dos Seven. Logo após ser admitida, ela sofre um abuso sexual de Profundo, um dos heróis pertencentes ao grupo e, então, percebe que a idealização da imagem moral dos Supers que ela tinha não passava de uma fantasia. Ela e Hughie acabam por se envolver romanticamente, mas o segundo, no começo da relação, não sabe que ela faz parte dos Seven, conhecendo apenas a identidade de Annie como uma jovem garota "normal". Quando ele descobre que Annie e Luz-Estrela são a mesma pessoa, eles relutam em ficar juntos, dada as complicações da relação. Entretanto, pela frustração que Luz-Estrela teve ao se deparar com a realidade dos Seven, ela se aproxima de Hughie e decide colaborar com os Boys na destruição da Vought. Assim, os dois personagens aqui citados começam uma relação entre idas e vindas, pois um dos membros dos Boys, Butcher, repudia a relação por não acreditar nas boas intenções de Annie, já que ela é uma super-heroína.

Outros personagens que compõem os Seven são: Translúcido (Alex Hassel), Black Noir (Nathan Mitchell) e Rainha Maeve (Dominique McElligott). Os dois primeiros são um pouco menos relevantes no contexto geral, mas a terceira tem um arco interessante ao longo das duas temporadas. Ela é apresentada como ex-namorada de Capitão Pátria, que cumpre seu papel, quando convocada para salvar vidas. Entretanto, uma missão para salvar passageiros de um avião em queda, é o primeiro turning 
point de sua personagem, ou seja, o ponto de virada, o momento no qual ela toma consciência do erro que cometeu. Pressionada por Capitão Pátria, que estava na missão com ela, eles deixam centenas de passageiros morrerem, pois "daria muito trabalho levar todas as pessoas até a terra". Para minimizar os comentários negativos, a Vought manipula a situação, mas Maeve fica transtornada. A partir daí ela ajuda, ainda que não explicitamente, Luz-Estrela, que em determinado momento é indicada como traidora (após a descoberta de seu relacionamento com Hughie).

Outro aspecto relacionado a essa personagem é a questão da sexualidade. Apresentada ao público como ex-namorada de Capitão Pátria, no decorrer da narrativa descobrimos que Maeve é lésbica, mas mantém seu relacionamento escondido por medo de Capitão Pátria fazer algo contra "a única pessoa que ela ama". Porém, uma vez que esse relacionamento homoafetivo é descoberto, a Vought, de forma oportunista, utiliza-o para promover a "diversidade" no grupo e, assim, segundo eles, dialogar com um público mais amplo. Diante disso eles expõem a heroína a situações que beiram o constrangimento, como filmá-la sem que ela soubesse conversando em particular com a namorada e abordar sua orientação sexual em um filme sobre os Supers sem falar sobre isso com Maeve e de forma rasa, superficial e estereotipada.

Um dos elementos mais importantes da série, que é descoberto no desdobramento dos acontecimentos, é o Composto V, uma substância que confere aos Supers seus poderes. A história divulgada para a população é de que os heróis foram escolhidos por Deus para terem poderes especiais, mas a verdade é que 
a Vought injeta em bebês o Composto $V$, que faz com que as características marcantes dos heróis se desenvolvam. Entretanto, como todo experimento, nem sempre o resultado é bemsucedido. Então, eles mantêm, em sigilo, uma instituição, a qual podemos traçar um paralelo com um manicômio, para as pessoas que tiveram o Composto $\mathrm{V}$ injetado, mas não desenvolveram os poderes normalmente. A luta dos Boys passa a ser, então, tentar divulgar para a imprensa essa situação. Nessa missão eles ganham o apoio da congressista Victoria Neuman (Claudia Doumit) que, aparentemente, luta contra os Supers, mas ao final da segunda temporada, descobrimos que ela também tem poderes.

Existem ainda dois personagens que merecem destaque: Tempesta (Aya Cash) e Capitão Pátria (Antony Starr). A primeira é introduzida apenas na segunda temporada, mas é de grande importância para a narrativa da série. Sua identidade real como heroína era Liberty, mas depois de ter cometido um assassinato de cunho racista, ela se afasta dos holofotes e retorna com o nome de Tempesta, conseguindo, assim, se integrar aos Seven. Sua história, porém, contém raízes mais densas. Ao longo da segunda temporada descobrimos que ela, na verdade, tem 101 anos, uma idade muito maior do que aparenta ter, e que era casada com Frederick Vought, médico alemão, nazista e fundador da Vought International. Tempesta foi, então, a primeira super-heroína da Terra, tendo o Composto V sido criado por seu marido com o objetivo de criar uma "super-raça". Vought desertou da Alemanha no final da Segunda Guerra, indo para os Estados Unidos, onde se desenvolve o resto da narrativa.

Já Capitão Pátria é o super-herói que detém os maiores poderes e a capacidade de conseguir tudo o que quer. Um exemplo 
do nacionalismo americano encarnado no personagem que vende um discurso de união para os cidadãos, entretanto, está muito mais preocupado com a sua própria imagem. Capitão Pátria é o típico filho mimado que é incapaz de lidar com a frustração. Exceto pelo fato dele não ter que, de fato, lidar com ela, já que pode controlar tudo e todos. Ele cresceu em um laboratório, vinculado à Vought (agência que criou e cuida da carreira dos heróis), e seus poderes são fruto de experimentos científicos. Desse modo, ele cresce sem conhecer os afetos parentais próprios de uma criança. Tudo o que ele quer é ser o melhor, e, mais do que isso, que digam que ele é o melhor. Capitão Pátria não se importa em ter que passar por cima de pessoas inocentes ou se aproveitar de seus próprios colegas para conseguir o que quer. Ao final da segunda temporada, ele engata um romance com Tempesta, numa relação de cunho muito sexual e fomentada pelo fato de formarem uma dupla extremamente poderosa. Nessa mesma temporada, também é revelado que Capitão Pátria usa o Composto V para criar super-terroristas. Estes seriam os únicos com capacidade de competir com os Seven, tornando os embates mais interessantes, rentáveis para a Vought (que não estava a par desse plano) e buscando, com isso, exaltar a própria imagem de salvador.

Apesar de à primeira vista parecer que os Boys são os mocinhos e os Seven são os vilões, as narrativas encontradas na série são muito mais complexas. Ao mesmo tempo que fica difícil dar razão a um grupo ou a alguém, os motivos pelos quais as atitudes são tomadas são sempre muito claros. No livro Justiça: o que é fazer a coisa certa, Michael Sandel (2012) faz um mergulho filosófico e provocador nesse tema tão complexo, que pode ser a noção de justiça: 
É errado que vendedores de mercadorias e serviços se aproveitem de um desastre natural, cobrando tanto quanto o mercado possa suportar? Em caso positivo, o que, sé que existe algo, a lei deve fazer a respeito? O Estado deve proibir o abuso de preços mesmo que, ao agir assim, interfira na liberdade de compradores e vendedores de negociar da maneira que escolhem? Essas questões não dizem respeito apenas à maneira como os indivíduos devem tratar uns aos outros. Elas também dizem respeito a como a lei deve ser e como a sociedade deve se organizar. Para responder a elas, precisamos explorar o significado de justiça. (SANDEL, 2012, p. 13-14)

Embora a série não fale explicitamente nesse conceito, ela o tangencia na medida em que aborda a questão de heróis e vilões, onde os primeiros, supostamente fazem a justiça combatendo o mal causado pelos segundos. Entretanto, tanto em The Boys quanto no livro de Michel Sandel (2012), não é esperado que os espectadores/leitores escolham um lado, ou deem razão a um personagem específico. Todos fazem escolhas questionáveis de acordo com o que acham certo. Nem os heróis escapam das fragilidades humanas. Como disse Nelson Rodrigues: "Muitas vezes é a falta de caráter que decide uma partida. Não se faz literatura, política e futebol com bons sentimentos"3. Portanto, essa fronteira bem/mal aparece borrada, menos idealizada, embora cada ação evoque sua razão legítima, ou seja, quem a executa acredita que está fazendo o melhor na típica aplicação do velho ditado "os fins justificam os meios".

3 Frase retirada da coluna de Xico Sá na Folha de São Paulo. SÁ, Xico. As 12 melhores frases de Nelson Rodrigues. Folha de S. Paulo. São Paulo, 20 ago., 2012. Disponível em: https://xicosa.blogfolha.uol.com.br/2012/08/20/as-12-melhores-frases-de-nelsonrodrigues/comment-page-2/. Acesso em: 20 fev. 2021. 


\section{DO SÉCULO XIX AO SÉCULO XXI: AS NARRATIVAS QUE SE REPETEM E DIFERENÇAS QUE SE CONSTITUEM}

No texto "O pintor da vida moderna" Charles Baudelaire (1991) cita uma frase do escritor francês Stendhal: "O belo não é senão a promessa da felicidade" (p. 105). A série tratada neste artigo traz, exatamente, o oposto: tudo o que não é belo, o que não é discutido, o que não é feliz. Além desse recorte, esse texto de Baudelaire traz um outro aspecto interessante para pensarmos The Boys, mas dessa vez em sua estrutura narrativa. O escritor e poeta francês idealiza o pintor da vida moderna que faz uma obra crítica, registrando os excessos e a artificialidade do mundo nobre, principalmente. Logo no início, ele menciona sobre pessoas que vão ao museu, veem duas ou três salas e afirmam que já conhecem o museu. Em parte, isso acontece porque temos a tendência de tomar a parte pelo todo. Entretanto, outra razão que nos faz chegar à conclusão de que já "conhecemos o museu" após duas ou três obras é a repetição de um padrão existente nessa estrutura. Transpondo essa ideia para a literatura ou para as narrativas cinematográficas, também podemos encontrar um padrão que se repete desde os romances do século XIX.

As histórias, em geral, têm um casal para ser reunido, nos levando a uma espécie de "torcida" para vê-los finalmente juntos, um elemento para atrapalhar o relacionamento dos protagonistas, um vilão ou uma dupla de vilões, uma mãe que projeta seus desejos na filha, uma jovem ingênua, um rapaz nerd, uma grande reviravolta. Enfim, são vários elementos comuns que compõem muitas das narrativas antigas e atuais, e que nos fazem, muitas vezes, conhecer os desfechos mesmo sem ver as obras inteiras. 
The Boys não foge dessa realidade. Entretanto, a história coloca em xeque algumas estruturas muito bem estabelecidas como a dicotomia herói/vilão. Sendo assim, melhor de que pensar em estereótipos, que pressupõem uma estrutura fechada, talvez seja mais interessante, na narrativa de The Boys trabalhar com a ideia de arquétipos de Carl G. Jung (1991).

Criador da Psicologia Analítica, Jung, numa dissidência ao pensamento psicanalítico freudiano, nos traz a ideia de um inconsciente coletivo que representa as camadas mais profundas do inconsciente, uma estrutura comum aos seres humanos independente das diferenças, que carrega as marcas e raízes da humanidade, numa espécie de estrutura arqueológica, "matrizes arcaicas onde configurações análogas ou semelhantes tomam forma" (SILVEIRA, 1990, p. 77). Portanto, ao longo da história da humanidade no planeta, vencer adversidades é uma constante. $\mathrm{O}$ arquétipo do herói se constitui em nosso imaginário como aquele que luta, não esmorece, transcende batalhas em nome de uma causa; já o arquétipo que compõe os vilões, emerge da sombra, evoca os nossos aspectos obscuros, o que muitas vezes queremos rechaçar, mas que integra a nossa totalidade. É nesse trânsito entre luz e sombra, heroísmo e vilania que se instauram muitas das narrativas ficcionais, transformando nossa passagem pelo mundo, nossa luta pela sobrevivência numa saga repleta de tramas e dramas. Considerando as narrativas audiovisuais, Sílvio Anaz (2018), nos aponta:

É no roteiro que se encontra o conjunto de elementos simbólicos que estabelece a estrutura arquetípica da narrativa, isto é, a forma como esse 
conjunto de elementos, dentre os quais destacamse os arquétipos e estereótipos, com suas funções dramáticas e psicológicas, articula-se para contar uma determinada história e estabelecer o núcleo do imaginário que o autor propõe compartilhar com a audiência. Apesar de materializar-se em palavras, um roteiro para um filme ou uma série de TV é pensado a partir de imagens e destina-se principalmente a construir imagens. As imagens mentalizadas pelo criador são por meio do roteiro transmitidas e recriadas pelos demais interlocutores na produção de uma obra audiovisual, como diretor, elenco, figurinistas, maquiadores, editores, produtores e executivos do estúdio, até ser finalmente materializada na tela e compartilhada com a audiência. (ANAZ, 2018, p. 102)

Considerando tais elementos, há toda uma história contada em The Boys que envolve um jogo de palavras e imagens, conferindo uma dinâmica onde os arquétipos de bem e mal, são também problematizados. Ao contrário de certas séries televisivas como, por exemplo, Super-Homem ${ }^{4}$ onde a figura do herói com conflitos tipicamente humanos, porém, tendendo sempre à ética e à moral, fica bem delineada, em The Boys, os heróis têm seu lado corruptivel, sua sombra perturbadora, trazendo-nos questões que podem perfeitamente caber na realidade contemporânea. Nesse sentido, os personagens da referida série não são estereotipados como já alertado no início desse tópico, fugindo do lugar comum, ou da receita fácil, puramente comercial que, por vezes, povoa o universo audiovisual, principalmente, o televisivo.

4 Super-Herói americano retratado em histórias de quadrinhos, em séries televisivas e filmes desde 1938 até os dias atuais. É um personagem caracterizado pelas boas ações e por salvar a Terra dos perigos advindos das "forças do mal". 
Parte significativa das narrativas audiovisuais, no entanto, apresenta protagonistas que não são arquetípicos (redondos/complexos), e sim estereotipados (planos/bidimensionais). 0 estereótipo, nesta perspectiva de construção de personagens nas narrativas audiovisuais, deve ser entendido como uma degradação dos arquétipos. Isto significa que, enquanto o personagem arquetípico, composto por um ou vários arquétipos, apresenta características psicológicas, morais e comportamentais contraditórias (positivas e negativas), o personagem estereotipado apresenta apenas um desses aspectos (positivo ou negativo). (ANAZ, 2020, p. 264)

Mais adiante, o autor complementa a reflexão:

É um equívoco, portanto, entender que personagens unidimensionais, como o herói que apresenta apenas traços positivos ou o vilão com características unicamente negativas, sejam respectivamente representações do arquétipo do herói e da sombra. Na verdade, eles são estereótipos, pois apresentam apenas uma das dimensões de seus arquétipos, enrijecendo a dinâmica que os arquétipos necessariamente impõem aos personagens, fazendo-os oscilar psicológica, comportamental e moralmente entre características positivas e negativas. (ANAZ, 2020, p. 264)

Portanto, há uma riqueza na construção desses personagens que os mantém numa dimensão mais complexa. Se considerarmos os conflitos da sociedade pós-moderna, podemos refletir acerca do bem e do mal não mais como antítese, mas como experiências coexistentes. The Boys nos convoca à perda da ingenuidade nos levando a experimentar sentimentos conflitantes, tais como a 
simpatia por um personagem capaz de cometer atos ilícitos ou a irritação por aquele que pode querer tudo "certo" (aqui entre aspas por não podermos afirmar o que é certo). Talvez a saga heroica tenha dado lugar a saga mundana, repleta de desvios e tentações. Ao analisarmos dessa forma, criamos um espectro maior de transitoriedade que traz aos personagens a complexidade necessária para uma identificação maior com o público, ainda que se trate de uma série de ficção científica.

\section{SÍMBOLOS DA VIRTUDE E DA FORÇA NA BERLINDA}

A frase "In God We Trust" (Em Deus Confiamos) é considerada um dos lemas nacionais dos Estados Unidos da América. Em 1956, no Congresso, ela foi designada para ser a máxima americana, não substituindo, entretanto, uma outra expressão que era considerada o único lema nacional até então: "E pluribus unum" (De muitos, um). A primeira frase citada aqui, porém, é hoje uma das mais conhecidas, tendo sua magnitude exemplificada na impressão dessa expressão nas moedas e cédulas de papel. Eduardo Simões e Jorge Martins (2017) afirmam que:

A ideia partiu de um clérigo protestante que pregava que aquele conflito 'era um castigo divino contra o país porque a Constituição não havia mencionado Deus' em sua carta. À exemplo dessa, muitas outras leis foram aplicadas com o intuito de adoração e serviço a Deus. Como, por exemplo, a lei estadual que proibia a inclusão de lições sobre o evolucionismo. (SIMÕES; MARTIS, 2017, p. 8)

Diante dessa pequena exposição, podemos ter uma singela noção da importância que a figura de Deus tem na sociedade 
norte-americana. E é, justamente, sob esse mote que podemos dizer que a série tem o seu pilar, já que a população de The Boys acredita que algumas pessoas são escolhidas por Deus para terem superpoderes. Essa não é a única menção que a série faz sobre a religião. Os criadores fazem uma sátira com tons críticos de algumas ideias radicais disseminadas por Igrejas cristãs fundamentalistas. Logo na primeira temporada, somos apresentados a Ezequiel, um pastor que também tem poderes e que prega sobre a "cura gay". Entretanto, alguns capítulos depois, descobrimos que ele se relaciona com homens. Podemos ver também o laço entre Annie e a Igreja se desfazendo. Ela é uma das pessoas que acredita ter sido "escolhida por Deus" para ter poderes. Essa foi a história contada por sua mãe que sabia a verdade: a Vought procurou sua família quando Annie ainda era um bebê e Ihe injetaram o Composto V para que ela se tornasse uma Super. Porém, até descobrir a verdade, a personagem mantém uma relação de fé com Igreja comandada por Ezequiel, mas aos poucos ela vai se dando conta da hipocrisia presente nas relações ali travadas, principalmente, quando é obrigada a dizer que ainda é virgem (quando não é) para um grupo de jovens durante um evento cristão. Momentos depois, insatisfeita e revoltada com a situação, durante sua aparição no palco Luz-Estrela/Annie (temporada 1, episódio 5) diz:

Cada palavra que eu digo aqui está escrita em um script. Eu não escrevi nenhuma dessas palavras. Eu nem sei se acredito nelas. Quer dizer... Eu acredito em Deus, eu amo muito Deus, mas... Sinceramente... É que todos aqui têm tanta certeza de tudo... O ingresso mais barato aqui custa 170 dólares para que essas pessoas possam lhes dizer como ir para o Céu? Como elas sabem? Como alguém sabe? 
Quando a Bíblia foi escrita, a expectativa de vida era de 30 anos. Não sei se devemos interpretar tudo literalmente. Ela também diz que é pecado comer camarão. Se você for gay ou se você for Ghandi você vai para o inferno? E se fizer sexo antes do casamento... isso não é imoral, é humano. O que é imoral é o cara que meteu o pinto na minha cara. Aqui vai a verdade: qualquer um que diz saber a verdade está mentindo. E eu sei, eu sei que eu deveria ser essa heroína exemplar, mas eu não sei que diabos estou fazendo. Eu estou tão assustada e confusa quanto todos vocês. Eu cansei de fingir e cansei de aturar essa merda. Obrigada. (THE BOYS, 2019, Temporada 1, Episódio 5, 44:15/47:32)

Não bastasse a crítica feita à Igreja Cristã na primeira temporada, na segunda somos apresentados à Igreja do Coletivo, a qual podemos traçar um paralelo com o que seria a cientologia. É nessa Igreja que Profundo se refugia, depois de ter sua imagem exposta no caso de abuso sexual com Luz-Estrela. Lá os integrantes estimulam o Super ao uso de drogas para induzirem revelações e encontram uma esposa para que ele recupere sua imagem. Totalmente absorto pela atmosfera, ele ainda leva TremBala, quando este é retirado dos Seven, para entrar na Igreja do Coletivo. O que consideramos relevante, ao trazer esse aspecto exposto pela série, é uma forte crítica à um dos símbolos mais proeminentes da cultura norte-americana. A crítica, entretanto, não é feita à Igreja como um templo de renovação da fé, mas sim às distorções que a instituição tem revelado na sociedade moderna, assumindo papéis político-ideológicos e atendendo muito mais aos interesses dos homens do que de Deus. Eli Pimenta (1984), exemplifica esse fato: 
Uma vez que a Igreja 'não quer comprometerse na vida prática econômica' e assume a função de ser 'a muleta do Estado moderno' ela passa a ter funções intelectuais, políticas e ideológicas bem definidas de defesa do Estado moderno e das relações econômicas que constituem o seu conteúdo material. (PIMENTA, 1984, p. 67)

Outro símbolo cultural muito forte dos Estados Unidos, com o qual a série mexe, é o exército militar. A vice-presidente da Vought na primeira temporada, Madelyn Stillwell (Elisabeth Shue) defende, junto com Capitão Pátria, a possibilidade dos SuperHeróis integrarem o exército norte-americano. Essa ideia ganha força, depois que soldados americanos são aniquilados por um super-terrorista. A partir desse episódio, a Vought e Capitão Pátria, insistem que a presença de Supers no Exército impediria que tal ameaça se repetisse, tornando-os imprescindíveis para a proteção da nação estadunidense.

A própria representação do grupo de militares no cinema norte-americano deixa claro o sentimento de grandeza na missão de defender o país. Paula Broda (2015) destaca que logo após a entrada dos Estados Unidos na Segunda Guerra Mundial, o então presidente Roosevelt criou o Office of War Information (Escritório de Informação de Guerra), que tinha várias divisões (rádio, tv, cinema...) para produzir um material informativo sobre a guerra. Segundo Walter Pereira (2012) a divisão de cinema já estava em contato com Hollywood para a produção de filmes de propaganda de guerra. Para isso, alguns termos foram estabelecidos. Dentre eles, salientamos: as justificativas da guerra, os motivos da entrada dos EUA no conflito; apresentar quem era os inimigos e 
como atuavam; qual era o papel de cada cidadão naquela guerra e os sacrifícios que eram necessários para ajudar no conflito; objetivos e o desempenho das Forças Armadas dos EUA nas batalhas (PEREIRA, 2012).

Assim, uma interpretação possível da tentativa dos heróis de entrarem nas forças militares seria a insuficiência destas em lidar com os conflitos sozinhas. Sendo, portanto, os Super-Heróis melhores, ou superiores, do que o exército norte-americano. Os autores, então, enfraquecem o discurso militar, e abalam mais um pilar da cultura estadunidense. Tanto a Igreja quanto o Exército não são temas centrais da série, mas, junto com outros elementos, elas dão forma para a sustentação dos subtextos nem sempre sutis que The Boys traz.

Considerando que essas alusões à Igreja e ao exército não constam no argumento original da série advinda dos quadrinhos, há uma certa ousadia - ou transgressão - em colocar tais símbolos que representam a virtude (dedicação à Igreja) e a força (confiança no exército militar) da cultura norte-americana na berlinda. Nesse sentido, há não somente uma desconstrução de instituições ideais, mas, sobretudo, um certo abalo nessa fronteira entre o bem e o mal, uma forte tonalidade da versão televisiva da série que dialoga com a realidade.

Será esse um dos pontos que atrai tantos espectadores? Podemos pensar que esse século está marcado por uma certa ode às distopias em detrimento às utopias do passado? Que impactos isso nos traz? Certamente não é objetivo desse artigo buscar responder essas questões, porém, ao levantá-las aqui apontamos 
uma certa sobreposição de ficção e realidade com contornos mais fortes no campo do entretenimento. Com o advento da internet e das redes sociais, a despeito das chamadas fake news, não é raro nos depararmos com notícias que discorrem sobre imposturas na Igreja ou abusos cometidos pelas Forças Armadas que deveriam proteger a população. Há, então, uma aproximação tão desconfortável quanto indiscutivel entre The boys e a vida real.

\section{OS FINS JUSTIFICAM OS MEIOS! (?)}

Considerado por muitos o "pai" do pensamento político moderno, Nicolau Maquiavel defendia, de maneira simples e direta, que um Estado forte depende de um governante eficaz. Em sua obra "O Príncipe" o autor propõe que um governante deve agir segundo a moral sempre que possível, mas infringi-la se necessário, para a manutenção do poder (MAQUIAVEL, 2011). Ao que vemos exposto na série, parece que a lógica proposta por Maquiavel no século XVI nunca saiu de cena.

Retomando o que foi colocado na apresentação da série, nenhum personagem age em vão. Todos têm motivos muito claros para alcançarem seus objetivos, para lutarem por aquilo que acreditam. O que leva o espectador a ficar em conflito são, justamente, os meios pelos quais eles recorrem para conseguirem o que querem. Nenhum personagem de The Boys age de maneira íntegra durante toda a série. O que não significa que não ajam de maneira coerente. No xadrez há uma jogada conhecida como "gambito da rainha" (que ficou mundialmente famosa devido à série que leva o mesmo nome ${ }^{5}$ ), que consiste no sacrifício de uma 5 O GAMBITO da Rainha. Direção: Scott Frank. EUA: Netflix, 2020. Disponível em: https:// www.netflix.com/title/80234304tflix. Acesso em: 20 fev. 2021. 
peça para tirar vantagem disso mais na frente. O enxadrista sabe que irá perder uma peça, ele não age de maneira inconsequente, ou impulsiva, mas ele faz isso com uma finalidade. Em The Boys podemos dizer que são poucas as ações inconsequentes. Sacrifica-se a lealdade, a moral, a ética, e até a lei com a perspectiva de lutar pelo que acreditam - cada personagem com a sua visão - ser o certo. Assim nossa intenção não é comparar uma jogada estratégica de Xadrez que, obviamente, possui suas particularidades e contexto próprio, com a estratégia narrativa da série. Pensamos, na verdade, nessa jogada como uma metáfora da vida, um campo de forças no qual as ações geram consequências e onde a ficção e realidade podem confluir.

Em geral, a frase de Maquiavel é lida de forma superficial. Os "fins" podem até ser em prol do bem geral, mas os "meios" são essencialmente ruins. $O$ que a série nos faz questionar não são as ações ruins realizadas pelos personagens pois, mesmo quem negue a frase do pensador do século XVI, já se utilizou dela em algum momento. Um exemplo simples e rápido, quem nunca avançou um sinal tarde da noite? Ou atravessou a rua fora da faixa de pedestres? Analisando de forma estreita, essas medidas são incorretas, já que avançar o sinal é ilegal e atravessar fora da faixa é incorreto. Entretanto, se analisarmos outras variáveis como a violência, ou a pressa e a suposta falta de perigo, podemos entender o porquê dessas ações terem sido tomadas.

Claro, que não seremos levianas em comparar as ações dos personagens com um avanço de sinal. Para atingirem seus objetivos os Supers e os Boys vão quase ao extremo dessa lógica, inclusive matando pessoas - ou heróis - quando preciso. 
Entretanto, o que é interessante de pensar dentro dessa lógica, que entendemos como um deslocamento que a série provoca das dicotomias já aqui citadas, é que a pergunta "eles estão certos ou errados?" é quase impossível de ser respondida. Assim como, é quase impossível de responder se a pessoa que avança o sinal de madrugada está certa ou errada ou se sacrificar uma peça no xadrez é uma jogada certa ou errada.

Essa percepção nos leva à uma questão central para o desenvolvimento do sujeito moderno: a questão da escolha. Com a transição do século XVII para o século XVIII temos a ascensão do movimento iluminista, o qual se baseava em uma série de ideias centradas na razão. Atrelado à Revolução Científica, esses movimentos ressignificaram a existência do homem no mundo. Antes pautada única e quase exclusivamente pela religião, o homem passava a ser o centro e a buscar respostas para as questões que, até então, eram justificadas somente pela fé (MELLO; DONATO, 2011).

Desse modo, o sujeito moderno se torna agente de sua própria vida e, portanto, responsável pelas suas próprias escolhas. É importante ressaltar que toda escolha que fazemos está relacionada à uma situação, e toda situação está dentro de uma circunstância. Assim, o objetivo aqui não é pregar nenhum tipo de julgamento moral, mas retomar a ideia sartreana de que o homem é livre e responsável pelas suas escolhas (SARTRE, 2013). Essa filosofia desmonta uma frase muito utilizada quando o homem não consegue bancar seu posicionamento: "eu não tive escolha". Essa frase é, também, quebrada em The Boys onde essa noção da escolha vai ficando mais clara na medida em que a trama 
vai se desenvolvendo e os personagens se enredando com seus objetivos. Uma cena que reflete esse ponto de vista é quando Hughie, o personagem mais ingênuo dos Boys, que vai sendo envolvido (não sem ter responsabilidade nisso), em situações nas quais ele não domina, mata um dos Supers. Era de se imaginar que Butcher, Mother's Milk e Frenchie, fizessem essa ação, mas não o jovem menos experiente e, principalmente, provido do que nós chamamos de "bom caráter".

A cena mostra que Hughie não faz isso sem querer. Ele, no momento em que aperta o botão para explodir o Super-Herói Translúcido, tem consciência, não apenas do ato em sim, mas das consequências de sua escolha. O integrante dos Seven tenta convencer Hughie a deixá-lo ir dizendo que ele será visto como o "herói" que salvou Translúcido e poderá voltar para a sua família, ainda que isso significasse trair a confiança dos Boys. Hughie desiste de apertar o botão e, quando vê o Super-Herói indo embora e ficando invisível (esse é o seu poder) ele olha para um cartaz na cozinha da casa que estão com os dizeres "keep your hands clean" (mantenha suas mãos limpas), respira e, então, aperta o botão matando Translúcido. É interessante notar o jogo de significações proposto pela série. Manter as mãos limpas, para Hughie naquele momento, é não trair os seus parceiros, o que naquelas circunstâncias significava matar o Super-Herói. Ele sabia que a morte de Translúcido traria consequências severas aos Boys, que estavam escondidos e seriam (e de fato foram) encontrados, já que o Capitão Pátria estava por perto e a explosão fez com que ele encontrasse a casa. Entretanto, diante dessas duas possibilidades (correr o risco de serem encontrados e trair seus colegas), Hughie 
fez a sua escolha. E o mais interessante é que não há um sentimento posterior de culpa pela ação tomada, ratificando a noção da consciência na hora do ato e, além disso, da clareza das razões pelas quais ele escolheu matá-lo.

Acompanhar essas cenas e descrevê-las aqui traz uma materialidade à afirmação de Maquiavel que sai do plano filosófico para o campo da ação. Como em outros fatos famosos da história - o lançamento da bomba atômica na cidade japonesa Hiroshima, por exemplo - essa proposição é colocada a serviço do bem. No entanto, constata-se, nessa lógica, um irrefutável entrelaçamento entre o bem e o mal.

Na cena narrada, qualquer escolha de Hughie poderia ser considerada boa ou má. Assim, a questão, nesse caso, não é o julgamento moral dos meios utilizados, mas sim a responsabilidade da decisão que o próprio personagem considerava ser a melhor (ou menos pior) para atingir seus objetivos. Desse modo, seja numa decisão individual - no caso de Hughie, nosso personagem da ficção -, seja numa decisão institucional - o lançamento da bomba atômica, fato real, histórico, cujos efeitos destrutivos reverberam até hoje - mais do que a dimensão da moralidade das ações, estamos propondo uma reflexão acerca da dimensão da escolha e da responsabilidade que ela produz em cada situação.

Portanto, nesse recorte aqui efetuado, não estamos nos atendo à coerência de Hughie, já que qualquer decisão que ele tomasse, seria verossímil em relação ao arco do personagem durante a série. O que ressaltamos refere-se à esfera existencial, um dos conflitos do sujeito moderno, pois seja para um lado ou outro, ele precisou 
decidir. E toda tomada de decisão implica, necessariamente, em uma escolha. Como dito anteriormente, é uma ação realizada por um personagem inesperadamente, tanto para os seus parceiros na série, quanto para o público que o vê como o mais inocente dos quatro integrantes dos Boys. Isso reforça a nossa proposta de pensar nessas questões para além de uma visão estreita e dicotômica, e sim por um olhar ampliado. Pois, sob a perspectiva, um personagem "bom" (Hughie) praticou uma ação "ruim" (matar alguém). Entretanto, como exposto nesse espaço, ao olhar apenas sob esse viés perdemos uma gama de possibilidades e subtextos que permeiam as escolhas tomadas.

Separar essas questões apenas sob a ótica da dicotomia bem/mal pode se constituir em uma narrativa perigosa, trazendo invisibilidade à responsabilidade da decisão. Isso nos leva, novamente, ao esmaecimento dessas fronteiras, o que pode trazer amplitude aqui o bem do mal, é apenas uma tentativa de amenizar a ação. Isso pode se constituir em uma narrativa perigosa, trazendo invisibilidade a responsabilidade da decisão.

\section{CONSIDERAÇÕES FINAIS}

Dentre as inúmeras possibilidades de reflexões que The Boys nos proporciona, escolhemos nesse artigo abordar algumas questões estruturais, culturais e filosóficas que fazem com que a série seja tão pertinente, cativante e, principalmente, familiar ao espectador. Se tomarmos a máxima popular de que "a vida imita a arte", considerando heróis não totalmente virtuosos, vilões não totalmente cruéis e deslocando os estereótipos para os arquétipos, podemos pensar que The Boys faz um caminho 
de mão dupla. A arte também reverbera o que encontramos na vida, a chamada vida real. E há na arte uma potência de comunicar. Ainda que a compreendamos como livre, tal e qual a perspectiva sartreana, liberdade e responsabilidade estão intrinsicamente relacionadas.

O documentário "Arquitetura da Destruição" (1989), dirigido por Peter Cohen, narra, sobretudo, os ideais estéticos que sustentavam a ideologia nazista. Para Hitler a arte era uma ferramenta de poder. Ele a utilizava como uma política de condicionamento, como uma forma de opressão, para justificar o massacre de um povo, sob a ótica da beleza da purificação da raça ariana. Dessa forma, Hitler pregava construções padronizadas, esteticamente perfeitas, adequadas, harmônicas, simétricas. Todas com beleza, mas sem autenticidade. A arte, como coloca Walter Benjamin (2018), para continuar sendo arte, precisa ser autêntica. Por isso, por exemplo, que a quebra ocasionada pelas vanguardas é tão importante. É uma resignificação da arte, e do belo. É um uso político, mas não politizado. Hitler queria politizar a arte, e a arte politizada não é arte, é uma ferramenta de poder. Daí a responsabilidade do que produzimos enquanto arte, pois é fundamental que ela nos faça pensar, para além do consumo.

O cinema e a indústria de audiovisual inauguram outras linguagens que se tornaram muito fortes na era moderna. Singer (2001), nos coloca que a modernidade deixou marcas no cinema, trazendo as noções de simultaneidade, velocidade, superabundância visual e choque visceral. The Boys traz uma enxurrada de estímulos e efeitos visuais incríveis, mas é a narrativa traçada um dos grandes trunfos da série. O esmaecimento das 
fronteiras entre bem e mal tendo como dispositivo um grupo de Super-heróis é um tipo de subversão. Afinal, Super-heróis foram criados sob a égide da proteção, a missão de servir e salvar a humanidade. Mais do que discorrer acerca do bem e do mal, ou nos apontar as vulnerabilidades dos heróis, The Boys coloca em cena a manipulação desse discurso da salvação, da proteção de que há alguém a ser seguido, imitado e venerado. Muitos políticos se apoiam nessas premissas para chegar ao poder. Aliás, esse é, justamente, o mote da terceira temporada. Quando na última cena da temporada anterior descobrimos que uma congressista que atuava contra os Supers e a Vought, também era, na verdade, uma Super-Heroína nada virtuosa.

No livro A Cultura do Barroco, José Antonio Mravall afirma que: "O novo agrada, o nunca antes visto atrai, a invenção que estreia embeleza" (MRAVALL, 2009, p. 356). The Boys traz uma nova perspectiva para o mundo dos heróis e mesmo diante de tantas cenas violentas, consegue fazer os olhos dos espectadores brilharem. Expandindo o conceito de belo em Baudelaire, a série pode não trazer felicidade, porém traz a angústia e o alívio de quem sabe que está tratando de assuntos delicados, mas que precisam ser debatidos de maneira mais profunda e realista. "The Boys não é a série que a gente queria, é a série que a gente precisava", afirma um fã e crítico da série ${ }^{6}$.

6 CARDOSO, Carlos. Review: The boys, a série da Amazon baseada nos quadrinhos de Garth Ennis. Meio bit. [S. I.], 2019. Disponível em: https://tecnoblog.net/ meiobit/409538/resenha-the-boys-a-serie-da-amazon-baseada-nos-quadrinhos-degarth-ennis/\#: :text=The\%20Boys\%20n\%C3\%A30\%20\%C3\%A9\%20a,de\%20um\%20 tubo\%20de\%20ensaio. Acesso em: 20 fev. 2021. 


\section{REFERÊNCIAS}

ARQUITETURA da Destruição. Direção: Peter Cohen. Suécia, 1989.

[Documentário]. (1h 50min).

ANAZ, Silvio Antônio Luiz. Processo criativo na indústria do audiovisual: do roteiro ao imaginário. Galaxia, São Paulo, n. 38, p. 98-113, 2018. Disponível em: https://www.scielo.br/j/gal/a/ M6wJHhMrKCQww5Rf4rWyNqJ/?lang=pt\&format=pdf. Acesso em: 20 fev. 2021. ANAZ, Silvio Antônio Luiz. Teoria dos arquétipos e construção de personagens em filmes e séries. Significação, São Paulo, v. 47, n. 54, p. 251270, 2020. Disponível em: https://www.revistas.usp.br/significacao/article/ view/159964/161882. Acesso em: 20 fev. 2021.

BAUDELAIRE, Charles. O pintor da vida moderna. In: CHIAMPI, Irlemar (Org.). Fundadores da Modernidade. São Paulo: Editora Ática, p. 102-118, 1991. BENJAMIN, Walter. A obra de arte na era de sua reprodutibilidade técnica. Porto Alegre: L\&PM, 2018.

BRODA, Paula de Castro. Um Pato na guerra: a propaganda do exército estadunidense em Donald gets drafted (1942), Sky trooper (1942) e Commando Duck (1944). In: XXVIII SIMPÓSIO NACIONAL DE HISTÓRIA, Florianópolis. Anais [...]. Florianópolis, 2015.

JUNG, Carl Gustav. O eu e o inconsciente. Rio de Janeiro: Vozes, 1991.

MAQUIAVEL, Nicolau. O Príncipe. São Paulo: Companhia das Letras, 2011.

MARAVALL, José Antônio. A Cultura do Barroco. São Paulo: EdUSP, 2009. MELLO, Vico Denis; DONATO, Manuella Riane. O pensamento iluminista e o desencantamento do mundo: modernidade e a Revolução Francesa como marco paradigmático. Revista Crítica Histórica, Maceió, n. 4, p. 248264, 2011. Disponível em: http://www.revista.ufal.br/criticahistorica/ attachments/article/118/0\%20Pensamento\%20lluminista\%20e\%20०\%20 Desencantamento\%20do\%20Mundo.pdf. Acesso em: 20 fev. 2021. PEREIRA, Walter. O poder das imagens: cinema e política nos governos de Adolf Hitler e de Franklin D. Roosevelt (1933-1945). São Paulo: Ed. Alameda, 2012. 
PIMENTA, Eli. A Igreja na sociedade moderna segundo Gramsci. Perspectivas, São Paulo, v. 7, p. 59-73, 1984.

SANDEL, Michel. Justiça: O que é fazer a coisa certa. Rio de Janeiro: Civilização Brasileira, 2012.

SARTRE, Jean-Paul. O Existencialismo é um Humanismo. Rio de Janeiro: Vozes de Bolso, 2013.

SILVEIRA, Nise da. Jung - vida e obra. Rio de Janeiro: Paz e Terra, 1990.

SIMÕES, Eduardo; MARTINS, Jorge. Uma nação sob Deus: o sonho do fundamentalismo cristão nos EUA. In: CAMPOS, Breno Martins; SALLES, Walter Ferreira (Orgs.). Fundamentalismos Religiosos - Três abordagens distintas e complementares. Rio de Janeiro: Fonte Editorial, 2017.

SINGER, Ben. Modernidade, hiperestímulo e o início do sensacionalismo popular". In: CHERNEY, Leo; SCHWARTZ, Roberto (Org.). O cinema e a invenção da vida moderna. São Paulo: Cosac \& Naify, p. 95-126, 2001.

THE BOYS. Produtor: Hartley Gorenstein. Produtoras: Sony Pictures Television; Amazon Studios; Kripke Entreprises; Point Grey Pictures; Original Film; Kickstart Entertainment; KFL Nightsky; Productions. EUA: Amazon Prime Video, 2019. 